\title{
Os estudantes do ensino médio e as modificações corporais - um estudo exploratório
}

\author{
High school students and body modifications - \\ An exploratory study
}

Eveline Ximenes Tomaz*

Rui Neves**

\section{Resumo}

A grande maioria dos adeptos das Modificações Corporais (MC) são jovens e adolescentes. Objetivo: caracterizar o perfil dos jovens que possuem MC em escolas públicas de ensino médio na cidade de Sobral/CE/Brasil. Metodologia: pesquisa exploratória, de abordagem quantitativa, utilizando questionários com perguntas de escolha múltipla, com 20 estudantes. Os dados foram analisados através da estatística descritiva. Dentre os participantes, prevaleceu o gênero feminino, menores de idade; nível escolar abaixo do desejado; não participação em outros grupos (sub)culturais. Pode-se considerar as MC um texto cultural, que existe na rede textual da cultura corporal, sendo temática sugestiva dos estudos culturais na educação.

Palavras-chave: Modificação Corporal. Jovens. Nível de escolaridade.

\section{Abstract}

The vast majority of Body Modifications supporters are teenagers. Objective: to characterize the profile of students from public high schools in the city of Sobral / CE / Brazil who have body modifications. Methodology: exploratory research, quantitative approach, using questionnaires with multiple choice questions, with 20 students. Data

\footnotetext{
* Mestre em Educação Física e Saúde pela Universidade Católica de Brasília - UCB, Doutoranda em Educação pelo Programa Doutoral em Educação do Ramo Diversidade e Educação Especial na Universidade de Aveiro, Portugal; Professora na Universidade Estadual Vale do Acaraú, Brasil; Email: evelineximenes@ua.pt

** Doutor em Didática pela Universidade de Aveiro, Portugal; Professor do Departamento de Educação e Psicologia da Universidade de Aveiro, Portugal; Email: rneves@ua.pt
}

Conhecimento $\&$ Diversidade, Niterói, v. 11, n. 24, p. $10-35$

maio/.ago. 2019 
were analyzed through descriptive statistics. Among the participants, underage females prevailed; education attainment below the desired level; no participation in other (sub)cultural groups. MC can be considered a cultural text that exists in the textual network of the body culture, being suggestive theme for cultural studies in education.

Keywords: Body modifications. Teenagers. Education level.

\section{Introdução}

As Modificações Corporais (MC) são práticas milenares relacionadas com hábitos e costumes culturais. Ao longo dos anos, essas práticas foram sendo aderidas por pessoas de faixas etárias e classes sociais diversificadas, não mais apenas como simbologia de pertença a um determinado grupo, mesmo que essa opção continue a existir. As MC aqui consideradas são as tatuagens, piercings, alargadores, escarificações, brandings, suspensões, as consideradas radicais ou extremas.

Atualmente, as motivações para marcar o corpo não são mais, somente, as mesmas dos modern primitives ${ }^{1}$, se diversificando entre categorias como: beleza, arte, moda, individualidade, narrativas pessoais, resistência física, resistência social, pertencimento à grupos, espiritualidade, tradição cultural, vício, motivação sexual ou mesmo sem motivo específico (WOHLRAB et al., 2007). As MCs ainda são relacionadas a outras questões, que despertam preocupação, como as patologias (VOLPI, 2009), mas também são consideradas indicador de condicionamento físico, responsável por melhorar a aparência de uma pessoa no contexto da competição intersexual (ROGGENKAMP et al., 2017).

As MC apresentam um universo de simbologias que se expressam através do corpo, que é utilizado como vitrine (LE BRETON, 2003), ambos participam de um cenário que se insere duplamente na discussão cultural,

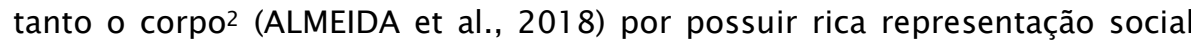

\footnotetext{
1 De acordo com Beatriz Pires (2005), o termo surgiu em 1967 "para indicar o modo de vida de indivíduos que, mesmo sendo membros de uma sociedade que se desenvolve baseada na razão e na lógica, se guiam pela intuição e colocam o corpo físico como o centro de suas experiências" (PIRES, 2005, p. 102).

2 A partir de uma revisão de sistemática em periódicos da Educação Física brasileira, Almeida et al.,
}

Conhecimento $\&$ Diversidade, Niterói, v. 11, n. 24, p. $10-35$ maio/.ago. 2019 
que se modifica de acordo com o tempo e o lugar, como as MC que podem ser consideradas como arte e estão relacionadas com a cultura de um povo. Seguindo um percurso em que se considera a relação existente entre o corpo, natureza e cultura, de imediato se relaciona as MC com o processo de formação do corpo (estetizado), ocupando lugar de importância no processo educativo, sugerindo que o tema possui relevância e merece fazer parte de reflexões no(s) espaço(s) da escola. Para Mendes e Nóbrega (2004), o reconhecimento dessa relação pode

[...] fornecer elementos para a construção de uma base epistemológica que articule argumentos para se pensar a educação a partir da compreensão do corpo humano na sua relação com o ambiente, cultura e sociedade em que vive, bem como o fenômeno da cognição como um texto corporal (p. 134).

Freire e Dantas (2012) acrescentam a importância de discussões acerca do corpo e suas práticas, entendendo que o corpo e sua representação constitui um elemento parte da formação do sujeito. Ampliando um pouco mais a relação do corpo com o cotidiano escolar, Farah (2010) elabora uma espécie de mapeamento dos espaços pedagógicos (teóricos, metodológicos e epistemológicos), em que se pode relacionar com/o corpo, permitindo a compreensão da complexidade e amplitude deste tema (corpo) no âmbito da vida/sociedade e do processo educativo, motivando a elaboração de um "currículo cultural'3 (COSTA et al., 2003, p. 57).

De acordo com Cegolon et al. (2010), estudos sobre MC mais recentes foram realizados com estudantes universitários com o objetivo de descrever características como gênero, idade, traços de personalidade e cultura, a prevalência e locais de onde se localizam as MC, em busca de

(2018) identificam 5 categorias de corpo, uma delas seria "Corpo e Representação", relacionado as representações do corpo nos artefatos culturais (revistas, jogos, sites, jornais etc.), práticas corporais e esportivas.

3 Para Costa et el., (2003) "Currículo cultural diz respeito às representações de mundo, de sociedade, do eu, que a mídia e outras maquinarias produzem e colocam em circulação, o conjunto de saberes, valores, formas de ver e de conhecer que está sendo ensinado por elas" (p. 57).

Conhecimento \& Diversidade, Niterói, v. 11, n. 24, p. 10 - 35 maio/.ago. 2019 
melhor conhecer esse público. Enquanto isso, Stirn e Hinz (2008) chamam atenção para os resultados de alguns estudos que tem associado as MC a comportamentos negativos, avaliando que grande parte das pesquisas foram realizadas com quantidade reduzida de participantes ou grupos marginalizados.

Nesse estudo, apresenta-se um percurso breve da trajetória das MC, em seguida, descreve-se algumas características do público aderente destas práticas. Essa pesquisa tem o objetivo de caracterizar o perfil dos jovens que possuem MC em escolas públicas de ensino médio na cidade de Sobral, no estado do CE (Brasil), contribuindo com o conhecimento desta prática que se multiplica entre este público e merece a atenção da comunidade educacional.

\section{Sobre as modificações corporais 4}

Considera-se MC todo tipo de alteração realizada na estética natural do corpo. Dentre essas alterações, existem algumas mais complexas e outras mais superficiais. Pode-se considerar complexas as que estão vinculadas a mudança de gênero (PINTO, et, al., 2017; SOUSA; IRIART, 2018), por exemplo, e todas as que são realizadas por intermédio de procedimentos cirúrgicos, como as cirurgias plásticas. Associam-se ainda, àquelas que consideramos complexas, as denominadas por alguns autores como extremas ou radicais, que dão ao corpo uma estética diferenciada do padrão/tradicional, não são cirúrgicas, mas são invasivas, (semi)permanentes, possuindo características, muitas vezes, de ser exótica, como o caso da split tongue, dos implantes de silicone, das suspensões, das perfurações nas bochechas ou de implantes de acessórios nos órgãos genitais.

De acordo com evidências históricas e arqueológicas, sabe-se que a tatuagem era utilizada em todo o mundo desde a Antiguidade (WOHLRAB et al., 2007; WOHLRAB et al., 2009; THOMPSON, 2015; AYANLOWO et al.,

\footnotetext{
${ }_{4}$ As modificações corporais (MC) as quais nos referimos são as consideradas, por alguns autores, como radicais ou extremas. São algumas delas: tatuagem, piercing, alargador, branding, escarificação, suspensão. Não são MC aqui consideradas, aquelas alcançadas por meio de cirurgia plástica, nem por meio de dieta e atividade física.
}

Conhecimento $\mathscr{E}$ Diversidade, Niterói, v. 11, n. 24, p. 10 - 35 maio/.ago. 2019 
2017). Os registros mais antigos da existência da tatuagem são de um corpo europeu mumificado naturalmente, Ötzi, e da múmia de Chinchorro na América do Sul (DETER-WOLF et al., 2016).

As modificações do corpo sempre existiram ao longo do tempo, compondo os hábitos e costumes culturais dos povos, pondo o corpo em cena, como diz Le Breton (2006), “o corpo é uma realidade mutante" (p. 28). No século XIX, as tatuagens eram presentes nos corpos circenses, já no século $X X$, essas marcas estavam vinculadas à imagem dos participantes de grupos marginalizados, como as prostitutas, presidiários, gangues e outros tipos de comportamentos de risco. $\mathrm{Na}$ segunda metade do século $\mathrm{XX}$, o significado de tatuar o corpo ganha nova dimensão, como símbolos de resistência contra aspectos da sociedade e suas formas de dominação. $\mathrm{Na}$ contemporaneidade, as MC assumiram novas simbologias, uma delas, podese considerar, que as marcas corporais foram transformadas em mercadorias, sendo objeto do consumismo contemporâneo (FERREIRA, $2014)$.

De acordo com Lirio (2007), no período pós-moderno, as MC estão relacionadas com algumas fragilidades desse tempo, as incertezas consequentes da modernidade, a relação com a criação do corpo simulacro, a tentativa de mudar a realidade começando pelo próprio corpo, considerando-se que o corpo é "um campo de encontro entre a natureza, os mitos e práticas ancestrais e as modernas tecnologias. Nele serão efetuadas intervenções com vistas a mudanças psíquicas e reinserções sociais" (p. 134). Para Roberts (2012), as tatuagens são ressignificadas entre os americanos desde o final dos anos 80 e início dos anos 90, momento que fica conhecido como "renascimento" das tatuagens, em que essas práticas não estão mais vinculadas apenas aos antigos sentidos/significados, mas qualquer pessoa resolve, por qualquer motivo, marcar o seu corpo.

Os objetivos/motivos de aquisição das modificações corporais são bem variados, como arte e expressão corporal, identificação, classificação militar, afiliação a gangues, marcação de prisioneiros ou memorização da história pessoal, entre outros (HENRY, CARSON, 2014). Armstrong et al. (2013) identificaram como principais motivos para a procura das MC, a 
intenção de reforçar a individualidade e formação da identidade, seguidos da representação como um símbolo de pertença ao grupo e assuntos religiosos. Consideradas como expressões emocionais visíveis, as marcas corporais causam nos adeptos várias sensações, uma delas seria a de se sentir especial e único.

Mesmo que, atualmente, o perfil dos adeptos das MC esteja passando por mudanças, desvinculando estas práticas dos aspectos negativos e apresentando perspectivas positivas, despertam curiosidade e cuidado. Curiosidade devido às novas formas de modificação que surgem, a cada dia, além do procedimento nada natural como elas são executadas; e cuidado, devido serem práticas invasivas que necessitam de cuidados pré e pós intervenção.

Para os profissionais de saúde, as MC são temas relevantes nos programas de Educação e Saúde (CEGOLON et al., 2010); na psicologia, esse tipo de MC tem deixado de ser considerada condição de patologia para contribuir com o conhecimento da auto-identidade, podendo ser valiosa no trabalho clínico (ROGGENKAMP et al., 2017), não sendo mais indicador de psicopatologia (PAJOR et al., 2015). Quanto ao olhar sociológico, sobre as MC, entende-se essas práticas como forma de buscar o reconhecimento social, relacionando-se com a estética do corpo-lugar onde o jovem experimenta a vida, devido ao caráter comercial que essas práticas assumiram no seu "renascimento", e é identificada por Ferreira (2014) como uma experiência incorporada.

No cenário educacional, as MC podem ser consideradas como texto cultural, "um conjunto de signos dotados de algum sentido" (NEIRA, 2011, p. 325), existente na rede textual da cultura corporal, entendendo a dinâmica da cultura de acordo com Costa et al., (2003): "Cultura deixa, gradativamente, de ser domínio exclusivo da erudição, da tradição literária e artística, de padrões estéticos elitizados e passa a contemplar, também, o gosto das multidões" (p. 36). 


\section{Quem são os adeptos das MC?}

A prevalência das MC dá-se no público jovem (MAYERS et al., 2008; CEGOLON et al., 2010; ROBERTS, 2015; CHACHA; KAZAURA, 2015), mas sabe-se que a adesão a estas práticas avançaram em meio a todas as faixas etárias e classes sociais (HEYWOOD et al., 2012), independentemente dos riscos à saúde causados pela forma (procedimento) como são executadas, seja por técnicas inadequadas, ausência de profissional especializado ou por falta de cuidados necessários (CHACHA; KAZAURA, 2015).

Clerici e Meggiolaro (2011) consideram que grande parte das pesquisas tem sido realizada com adultos e jovens com maior idade, sugerindo que novas pesquisas contemplem os adolescentes de menor idade. Em seguida, com afirmação contraditória, Heywood et al. (2012) considera que pouco tem se pesquisado sobre a tatuagem em adultos. Fato é que, à medida que essas práticas avançam, surge a necessidade de conhecer mais sobre o perfil dos adeptos, suas atitudes, riscos e motivações.

A produção científica referente a essa temática tem avançado, mas ainda se considera em processo de desbravamento, já que a procura pelas MC tem evoluído em todo o mundo, suscitando pesquisadores interessados pelo tema em vários países como os Estados Unidos (SURIS, 2007, KOCH et al., 2015), Itália (CEGOLON; XODO; MASTRANGELO, 2010; CLERICl; MEGGIOLARO, 2011), Alemanha (WOHLRAB et al., 2007), Coreia (HONG; LEE, 2017), Tanzânia (CHACHA; KAZAURA, 2015), Reino Unido (SWAMI et al, 2015) e Austrália (HEYWOOD et al., 2012), nos apresentando dados sobre o público adepto das MC, desde a motivação, perfil, e correlações de comportamentos.

Ainda de acordo com Heywood et al. (2012), pouco se sabe sobre as características dos indivíduos que fazem tatuagens. Dukes e Stein (2011) afirmam que essas pessoas possuem rendas mais baixas e comportamentos de risco (HONG; LEE, 2017), e consideram que as MC contribuem na formação da identidade (ROBERTS, 2012; SILVEIRA et al., 2016), além de serem grandes buscadores de sensações (WOHLRAB et al., 2007).

Conhecimento $\&$ Diversidade, Niterói, v. 11, n. 24, p. 10 - 35 maio/.ago. 2019 
Levando em consideração que os jovens e adolescentes são os que mais se envolvem com estas práticas, e que elas estão associadas à formação da identidade, a partir de decisões que marcam seus corpos "para sempre", entende-se a temática relevante para fazer parte de formações e reflexões no âmbito escolar, "um espaço de desenvolvimento humano e de acolhimento da diversidade" (KASSAR, 2016), onde o professor pode orientar sobre "ações que levem os alunos a formar seus próprios significados de movimento e linguagem" (FREIRE; DANTAS, 2012, p. 149).

\section{Metodologia}

O presente estudo trata-se de uma pesquisa exploratória, com o propósito de "proporcionar maior familiaridade com o problema em estudo" (GIL, 2017, p. 26). Devido tratar-se de uma das fases do processo de validação de um dos instrumentos a utilizar no nosso estudo - o inquérito pode-se considerar "o passo inicial no processo de pesquisa pela experiência e um auxílio que traz a formulação de hipóteses significativas para posteriores pesquisas" (MANZATO; SANTOS, s/d, p. 4); descritiva, pois "procura descobrir, com precisão possível, a frequência com que um fenômeno ocorre, sua relação e conexão com outros, sua natureza e características [...] trabalha sobre dados ou fatos colhidos da própria realidade" (MANZATO; SANTOS, s/d, p. 4); e baseia-se numa abordagem quantitativa, considerando que os "resultados das pesquisas quantitativas são dados empíricos, características da realidade social, que precisam ser integrados teoricamente" (RAMOS, 2013, p. 65), na perspetiva de perceber as características marcantes no perfil dos adeptos às MC.

\section{Participantes da pesquisa}

O estudo foi realizado em duas escolas públicas estaduais de ensino médio na cidade de Sobral, no estado do Ceará, situada no nordeste do Brasil. As escolas foram escolhidas de forma aleatória, respeitando apenas o critério de contemplar o ensino médio, levando em consideração a 
importância da faixa etária dos alunos, sendo este o público que interessa à pesquisa. Participaram da pesquisa 10 estudantes de cada escola, com o pré-requisito de possuírem qualquer $M C$, de ambos os gêneros, e que se disponibilizaram a responder o questionário com questões de múltiplas escolhas.

\section{Coleta dos dados}

Foram aplicados questionários com perguntas de escolha múltipla, junto de 20 estudantes ( 8 do gênero masculino e 11 do gênero feminino), com perguntas referentes ao perfil dos participantes como: gênero, idade, escolaridade e possível envolvimento destes jovens com outros grupos presentes na sociedade/comunidade as quais participam. $O$ instrumento foi elaborado com perguntas objetivas, na perspectiva de obter respostas igualmente objetivas, evitando provocar dúvidas nos participantes, considerando na ocasião que "o questionário deve ser previamente testado, mediante sua aplicação a um grupo pequeno, antes de sua aplicação ao conjunto dos sujeitos a que se destina [...]" (SEVERINO, 2007, p. 126).

\section{Análise dos dados}

Os dados foram analisados através da estatística descritiva com o objetivo de obter de forma clara uma primeira leitura dos dados, que provém de variáveis nominais (COUTINHO, 2016), permitindo evidenciar traços de definição de um perfil desses jovens estudantes quanto a idade, gênero, situação escolar, nível de escolaridade dos pais e adesão/participação em movimentos sociais.

\section{Resultados e discussão}

\section{Gênero e Faixa etária}

Dentre os estudantes que participaram da pesquisa, todos eles possuíam algum tipo de MC, sendo a maioria do gênero feminino (11 - $55 \%$ ),

Conhecimento $\&$ Diversidade, Niterói, v. 11 , n. 24 , p. $10-35$ maio/.ago. 2019 
8 (40\%) do gênero masculino. De acordo com Roberts (2015), a tendência atual é que o gênero feminino seja o mais propenso a ser tatuado.

Sendo as MC práticas imbuídas de pré-conceitos, consequência dos seus adeptos iniciais terem sido grupos controversos como criminosos e prostitutas, seguidos por punks e hippies, o fato de ser mulher faz com que o preconceito aumente, e isso implica na escolha dos desenhos e locais do corpo. A situação se agrava quando essas mulheres pertencem a classes populares, "fazendo com que o preconceito seja grande, devido ao fato de que as classes dominantes são as detentoras de valores e códigos, e, por isso, julgam as marcas dessas mulheres como inapropriadas e banais" (ANDRADE, 2015, p. 19). Desta forma, o fato das mulheres estarem aderindo com maior frequência a este tipo de prática, pode representar uma conquista por parte do gênero, como forma de se impor socialmente, aderindo ao que Ihe apraz, independente dos pré-conceitos à sua volta.

Tabela 1 - Perfil dos estudantes - idade e gênero

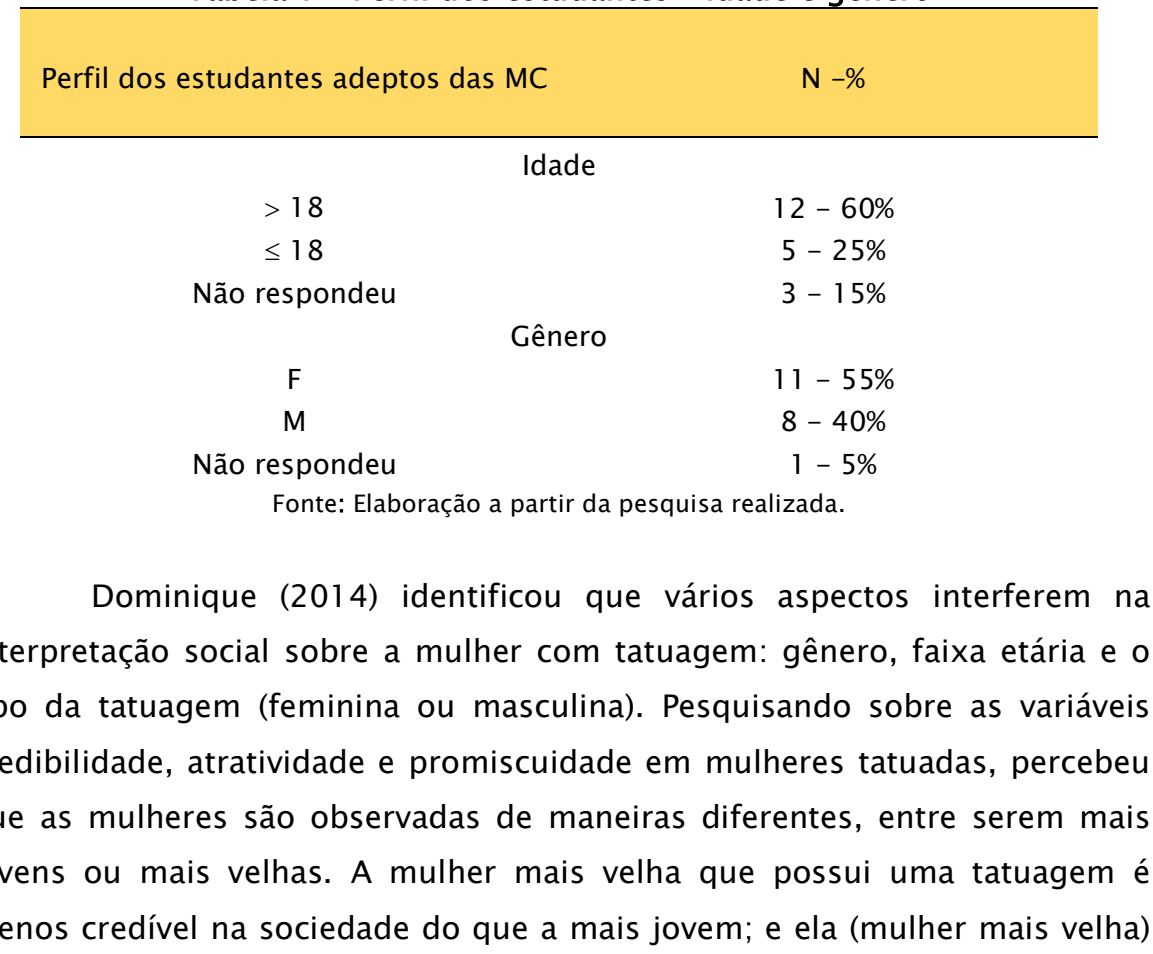

Conhecimento $\&$ Diversidade, Niterói, v. 11, n. 24, p. 10 - 35 maio/.ago. 2019 
só é considerada mais atraente quando não possui tatuagem, ou se possui, que a tatuagem tenha perfil feminino.

Quanto a faixa etária, a maioria são menores de idade (12 - 60\%). Na Itália, Cegolon et al., (2010) identificaram resultado equiparado numa amostra de 4277 estudantes: maioria feminina e prevalência de menores de idade. De acordo com Ferreira (2011), essa demanda elevada de jovens em busca das MC dá-se devido à adolescência ser um período em que eles buscam se afirmar de forma identitária e socialmente.

As tatuagens representam para os jovens um processo de transformação, como se elas começassem a desenhar uma nova identidade, "concretamente, podem configurar uma mudança de escola, de residência, a decomposição e/ou recomposição familiar, ou uma ruptura com a família de origem. São acontecimentos que implicam a transformação do círculo de relações dos jovens [...]" (FERREIRA, 2011, p. 141). Destarte, o currículo da escola como um projeto político com capacidade de formar novas gerações, não deve ser "apenas uma forma de transmissão cultural, é também um modo de posicionar os sujeitos no interior da cultura [...]; novas maneiras de comunicação entre comunidades e, portanto, de identidades [...]; compreender a interação entre a experiência subjetiva no mundo e as paisagens culturais nas quais as subjetividades se constroem" (NEIRA, 2011, p. 327).

Percebe-se que a tatuagem pode ser um acessório de livre escolha, mas também pode estar associada a condições de desestrutura emocional para os jovens. Roggenkamp et al. (2017) nos apresenta novas perspectivas quanto a adesão das MC, em especial as tatuagens, identificando-as não mais apenas como sinal de patologia, mas como aspectos importantes na formação da identidade dos praticantes/adeptos. Sugere que as tatuagens evoluíram como um indicador de condicionamento físico, participando como fator relevante nas relações sexuais. 
Tabela 2 - Perfil dos estudantes - atividade remunerada

\begin{tabular}{cc}
\hline Atividade remunerada & $\mathrm{N}-\%$ \\
\hline Sim & $4-20 \%$ \\
Não & $16-80 \%$
\end{tabular}

A maioria destes jovens (16 - 80\%) não exerce nenhuma atividade remunerada, enquanto os que exercem alguma atividade com renumeração são estágios ( 1 - 5\%), 2 (10\%) com contrato de trabalho temporário e apenas 1 (5\%) com contrato de trabalho indeterminado. A tatuagem foi negativamente correlacionada com valores como trabalho voluntário e estudo (CLERICl; MEGGIOLARO, 2011), e influenciam negativamente na perspectiva de emprego (ROBERTS, 2015). Em contrapartida, os resultados da pesquisa de French et al. (2018) sugerem que as tatuagens não estão significativamente associadas à discriminação no emprego.

\section{Nível de escolaridade}

Todos os participantes da pesquisa cursavam o ensino médio em escolas públicas: 2 (10\%) o primeiro ano, 12 (60\%) o segundo ano e 6 (30\%) o terceiro ano. O ensino médio é a etapa final do processo formativo da Educação Básica no Brasil. De acordo com a Resolução No 4/2010, essa etapa é dividida em três anos e a faixa etária ideal é de 15 a 17 anos. Apenas 30\% dos estudantes estão dentro da faixa etária e ano escolar ideal: 5 (25\%) alunos com 16 anos no $2^{\circ}$ ano, e 1 (5\%) aluno com 17 anos no $3^{\circ}$ ano. 
Tabela 3 - Relação entre faixa etária e ano escolar

\begin{tabular}{|c|c|c|}
\hline \multirow{2}{*}{ Ano ensino médio } & $\mathrm{N}-\%$ & Idade dos Estudantes \\
\hline $1^{\circ}$ & $1(5 \%)$ & $16 \mathrm{a}$ \\
& $1(5 \%)$ & $18 \mathrm{a}$ \\
\hline $2^{\circ}$ & $5(25 \%)$ & $16 \mathrm{a}$ \\
& $6(30 \%)$ & $17 \mathrm{a}$ \\
& $1(5 \%)$ & $19 \mathrm{a}$ \\
& $1(5 \%)$ & - \\
\hline $3^{\circ}$ & $1(5 \%)$ & $17 \mathrm{a}$ \\
& $1(5 \%)$ & $18 \mathrm{a}$ \\
\hline
\end{tabular}

Fonte: Elaboração a partir da pesquisa realizada.

15\% dos estudantes já deveriam ter finalizado o ensino médio: 2 (10\%) com 18 anos, um ainda está cursando o $1^{\circ}$ ano e outro o $3^{\circ}$, e 1 (5\%) aluno com 19 anos no $2^{\circ}$ ano. Percebe-se que, mesmo a maioria estando dentro da faixa etária ideal, existe um atraso quanto a estar cursando o ano de estudo ideal.

Numa pesquisa virtual com adeptos das MC, Roberts (2015) identificou baixo nível de escolaridade, menor probabilidade de frequentar a faculdade, e quanto à empregabilidade as "modificações, pelo menos entre as fortemente modificadas, podem contribuir para o desemprego e para as dificuldades financeiras" (p. 1108).

Entre modificados e não modificados, o desempenho acadêmico foi a principal diferença encontrada em Suris (2007), onde os adeptos das MC possuíam menor nível educacional, sendo as MC consideradas como prática desviante, associada ao uso de drogas e sexo de risco, não estando relacionada com tentativa de suicídio. Heywood et al. (2012), considerando questões sócio-demográfica e comportamentais de uma amostra considerável de homens e mulheres (16 a 64 anos), também identificou que, quanto maior o nível escolar, menor a possibilidade de adquirir tatuagem.

Conhecimento $\&$ Diversidade, Niterói, v. 11, n. 24, p. 10 - 35 maio/.ago. 2019 
A presença da tatuagem, uma dentre tantas MC - considerada mainstream por Ortega (2008), juntamente com o piercing, é alvo de preocupação no cenário educacional, sendo considerada uma prática comum entre os jovens da Pós-modernidade, em nome da supervalorização da imagem, em busca de chamar atenção e de parecer com os demais (símbolo de pertença e aceitação). Baliscei et al., (2015) ao relacionar o comportamento referente ao corpo na Pós-modernidade com as MC, a formação da identidade e a escola, analisa que os alunos, são sedentos de atenção, buscando aceitação e reconhecimento, inaugurando mudança de comportamentos e valores, desafiando os professores a reavaliarem suas práticas frente ao compromisso com o processo de formação.

Diante do cenário não ideal entre os adeptos das MC e o seu processo de aprendizagem, quando questionados sobre reprovação escolar em qualquer dos anos da educação básica, 5 (25\%) responderam já ter reprovado e 15 (75\%) nunca reprovaram nenhum ano, percebendo-se que, mesmo com dificuldades, eles têm acompanhado o processo de seriação da escola.

Nível de escolaridade dos pais

Tabela 4 - Nível de escolaridade dos pais

\begin{tabular}{|c|c|c|}
\hline Nível escolaridade & Pai & Mãe \\
\hline Ensino fundamental incompleto & $3(15 \%)$ & $2(10 \%)$ \\
\hline Ensino fundamental completo & $2(10 \%)$ & $3(15 \%)$ \\
\hline Ensino médio incompleto & $1(5 \%)$ & - \\
\hline Ensino médio completo & $7(35 \%)$ & $10(50 \%)$ \\
\hline Superior incompleto & - & - \\
\hline Superior completo & $1(5 \%)$ & - \\
\hline Não estudou & $2(10 \%)$ & $4(20 \%)$ \\
\hline Não sabe & $4(20 \%)$ & \\
\hline
\end{tabular}

Fonte: Elaboração a partir da pesquisa realizada.

Os pais possuem ensino médio completo na sua maioria (35\% dos pais e $50 \%$ das mães), e apenas $5 \%$ de ambos os gêneros possuem ensino 
superior completo. Percebe-se um baixo nível de escolaridade entre os pais, característica que, de acordo com pesquisas, possui relação direta com a adesão/interesse dos filhos pelas MC (CLERICl; MEGGIOLARO, 2011).

Para Dukes e Stein (2011) a educação dos pais afeta a opção de modificar o corpo, quanto menor nível educacional tem os pais, mais os filhos procuram as MC. E nos resultados de Cegolon et al., (2010) o nível de educação dos pais também prevaleceu o nível médio, resultado diretamente relacionado com o nível socioeconômico baixo ou médio.

Ao considerarmos as MC como elemento da diversidade, e associarmos ao âmbito de comprometimento da educação, somos impelidos a perceber que a escola tem um importante papel na partilha de informações que possam contribuir para as escolhas dos jovens, auxiliando na formação da identidade (CARVALHO, 2012). É importante que a escola seja um lugar que acolhe, que ensina, que escuta e esclarece, um lugar onde o jovem se sinta parte, uma escola que inclua, que ponha em prática o que Neira (2011) defende como educação inclusiva, respeitando a diversidade e a identidade como "fruto de um processo discursivo constituído em meio a circunstâncias históricas e experiências pessoais" (p. 328).

Parafraseando Kassar (2016), a educação é vista como aspecto fundamental para a diminuição das desigualdades sociais, é uma alavanca para o desenvolvimento econômico/social, percebendo-se o nível de importância deste equipamento social na (trans)formação da sociedade.

\section{Participação em grupos (sub)culturais}

Quanto a participação em outros grupos sociais, apenas 1 (5\%) declarou participar de um grupo de hip-hop, 3(15\%) deles identificaram-se como capoeirista e 16 (80\%) não participam de nenhum outro grupo (sub) cultural. Diferentemente dos resultados da pesquisa de Wohlrab et al. (2007), em que várias subculturas foram identificadas pelos entrevistados, incluindo motociclistas, hip hop, heavy metal, rastafarians, patinadores, góticos, hippies, punks, ravers, skinheads e "outros". 
Tabela 5 - Participação em grupos sociais

\begin{tabular}{|c|c|}
\hline & \\
\hline & $\mathrm{N}(\%)$ \\
\hline Esqueitista & - \\
\hline Patinador & - \\
\hline Capoeirista & $3(15 \%)$ \\
\hline Hip-Hop & $1(5 \%)$ \\
\hline Gótico & - \\
\hline Outros & - \\
\hline Nenhum & $16(80 \%)$ \\
\hline
\end{tabular}

Fonte: Elaboração a partir da pesquisa realizada.

A literatura sobre tatuagens entre adolescentes mostra que as tatuagens podem fazer parte de uma subcultura desviante (DUKES, 2016). Os entrevistados na pesquisa de Foster e Hummel (2000) não fizeram menção as MC como "expressões de ideologias subculturais", mas ao mesmo tempo, alguns dos participantes se identificaram como afiliados ao movimento LGBT (Lésbicas, Gays, Bissexuais, Travestis, Transexuais ou Transgêneros).

As subculturas tratam-se de grupos não normativos, de pessoas que tomam para si posturas fora do padrão em contestação a aspectos da estrutura social vigente, "essas pessoas assumem estilos diferenciados, é a maneira pela qual uma subcultura utiliza símbolos para demonstrar insatisfação com a cultura dominante" (ROBERTS, 2015, p. 1099), e toda subcultura possui ou é marcada por um estilo.

Afinal, as MC devem ser consideradas parte de uma subcultura, apesar de não somente pessoas de classe social baixa terem aderido a este tipo de prática, e sim pessoas de todas as classes e culturas, faixas etárias e gêneros? 


\section{Considerações finais}

Mesmo sendo uma prática milenar, as MC assumem um novo perfil no século XXI, não sendo, como outrora, apenas símbolo de pertença de um grupo, mas ganhando novos significados como sinal de embelezamento do corpo, moda, mercadoria no cenário do consumismo, parte da formação identitária dos jovens e adolescentes.

A adesão pelas MC por parte do gênero feminino, avançou, não apenas a perfuração do lóbulo da orelha, que já é instituído socialmente como uma prática natural do gênero, mas a adesão por parte de outras modificações, como as tatuagens e piercings, passam a fazer parte da estética corporal das mulheres. Esse aspecto pode ser um indicador representativo da mudança de comportamento feminino, uma espécie de conquista social do gênero, que ainda é, fortemente, alvo de pré-conceito.

Outro aspecto relevante no cenário das MC é a presença de menores de idade, faixa etária relacionada a um período de mudança, surgimento de dúvidas, comportamento rebelde, a necessidade de chamar atenção para si. As MC são, muitas vezes, associadas ao fato de ser diferente, aspecto que parece concretizar a necessidade de chamar atenção.

Parte desses jovens não cursam o ano letivo estabelecido para a sua faixa etária, ao tempo que conseguem acompanhar o processo educacional evoluindo nos anos, ou seja, com poucas reprovações. Apesar de se ter acesso ao nível escolar dos pais, não se pode fazer uma relação com o dos filhos, pois os mesmos ainda estão cursando o nível médio, período em que a maioria dos pais encerraram os estudos. Nas pesquisas se confirmam que jovens com MC possuem nível de escolaridade mais baixo do que o esperado, e são filhos de pais com histórico educacional equivalente. Percebe-se que existe uma relação inversamente proporcional entre essas variáveis, quanto menor o nível de educação, maior a procura pelas MC.

Esses jovens não desenvolvem atividades fixas remuneradas, somente estágios, situação que pode ser justificada pela prevalência da menor idade, mesmo já tendo sido constatado que o fato de possuir MC 
implica na empregabilidade, podendo ou não ser justificado pela presença de pré-conceito.

Apesar das MC ainda estarem associadas ao pré-conceito, pode-se conferir mudanças no perfil do público atual: não possuem, obrigatoriamente, comportamentos desviantes, nem vínculo com outros movimentos sociais em nome de ideologias contra o sistema social estabelecido, e realizam suas marcas corporais por motivos variados, não apenas como forma de protesto.

A temática das $M C$ já faz parte da literatura científica, de áreas do conhecimento como a psicologia, sociologia, antropologia e outras, podendo ser considerado uma espécie de tema transversal a ser discutido também no processo da formação educacional. Por ser um cenário ainda em descoberta, percebe-se a necessidade de socializar informações para que se previna danos e se esclareçam dúvidas, levando em consideração que a temática implica em questões individuais e comportamentais como formação de identidade, saúde, relação social e aspectos histórico, podendo contribuir para o melhor conhecimento das práticas e a desmistificação de algumas atitudes preconceituosas.

A escola é um "equipamento social que, por sua obrigatoriedade, faz parte do cotidiano da quase totalidade dos indivíduos de todas as classes sociais" (KASSAR, 2016, p. 1227) e acolhe os jovens e adolescentes por alguns anos, contribuindo com sua formação, inclusive da identidade. Dessa forma, entende-se que temáticas relacionadas à realidade deste público, merecem atenção por parte desta instituição formadora, fomentando reflexões/discussões e promovendo (in)formações para maiores e melhores esclarecimentos. Pode-se considerar as MC um texto cultural que existe na rede textual da cultura corporal e que poderá ser abordado por um currículo cultural, sendo temática sugestiva para os estudos culturais na educação.

Dentro das limitações do estudo, percebe-se a pequena quantidade de participantes, pois trata-se de uma etapa da pesquisa em andamento, isso infere que os resultados não devam ser generalizados.

Conhecimento $\&$ Diversidade, Niterói, v. 11, n. 24, p. 10 - 35 maio/.ago. 2019 


\section{Referências}

AGBOR, A. M.; AZODO, C. C.; NAIDOO, S. Ritual tooth modification among the Baka pygmies in Cameroon. Odontostomatol. v. 38, n. 151, p. 21-30, set. 2015. Disponível em: <https://www.ncbi.nlm.nih.gov/pubmed/26930771 > Acesso em: 10 abr. 2019.

ALMEIDA, Felipe Quintão; GOMES, Ivan; SAMPAIO, Amanda; MARINOTTE, Arielle. O corpo como tema da produção do conhecimento: uma análise em cinco periódicos da educação física brasileira. Movimento, Porto Alegre, v. 24, n. 1, p. 133-146, jan./mar. 2018. Disponível em: < http://dx.doi.org/10.22456/1982-8918.73680 $>$. Acesso em: 13 fev. 2019.

ANDRADE, Priscila Aparecida Martins. Mulheres e tatuagens: valores e intenções impregnados na construção do corpo feminino. 2015. $112 \mathrm{f}$. Dissertação (Mestrado em Educação Sexual) - Pós-graduação em Educação Sexual, Faculdade de Ciências e Letras, Unesp, Araraquara, 2015. Disponível em: <https://repositorio.unesp.br/handle/11449/132055 >. Acesso em: 10 mar. 2019.

ARMSTRONG, Myrna L. et al. Body arte education: the earlier, the better. The Journal of School Nursing, v. 30, n. 1, p. 12-18, mar. 2013. Disponível em: <https://doi.org/10.1177/1059840513480815 $>$. Acesso em: 8 fev. 2019.

AYANLOWO, Olusola et al. Growing trend of tattooing and its complications in Nigeria. International Journal of Dermatology, v. 56, n. 7, p. 709-714, jul. 2017. Disponível em: <https://doi.org/10.1111/ijd.13521>. Acesso em: 21 abr. 2019.

BALISCEI, João Paulo; STEIN, Vinícius; CHIANG, Chih Wei. Marcas na pele: reflexões sobre tatuagem, identidade e escolarização pós-moderna. Revista Digital do LAV, Santa Maria, v. 8, n. 3, p. 28 - 47, set./dez. 2015. Disponível em: <http://dx.doi.org/10.5902/1983734819673>. Acesso em: 30 abr. 2019. 
BRASIL. Ministério da Educação. Resolução no 4, de 13 de julho de 2010. Diretrizes Curriculares Nacionais Gerais para a Educação Básica. Conselho Nacional de Educação. Câmara de Educação Básica. MEC. Brasília, DF. Disponível em: $<$ http://portal.mec.gov.br/index.php?option=com_docman\&view=download \&alias =5916-rceb004-10\&category_slug=julho-2010-pdf\&ltemid=30192> . Acesso em: 6 fev. 2019.

CARVALHO, Mauro. A construção das identidades no espaço escolar. Revista Reflexão e Ação, Santa Cruz do Sul, v. 20, n. 1, p. 209-227, jan./jun. 2012. Disponível em: <http://dx.doi.org/10.17058/rea.v20i1.2161 >. Acesso em: 10 maio 2019.

CEGOLON, Luca; XODO, Carla; MASTRANGELO, Giuseppe. Characteristics of adolescents who expressed indifference or no interest towards body art. BMC Public Health, v. 10, n. 605, p. 2-6, out. 2010. Disponível em: <https://doi.org/10.1186/1471-2458-10-605>. Acesso em: 19 mar. 2019.

CHACHA, Emmanuel; KAZAURA, Method. R. Body-art practices among undergraduate medical university students in Dar Es Salaam, Tanzania, 2014. Indian Journal of Dermatology [on-line], v. 60, n. 2, p. 212, mar. 2015. Disponível em: <http://doi.org/10.4103/0019-5154.152567>. Acesso em: 22 mar. 2019.

CLERICI, Renata; MEGGIOLARO, Silvia. The context of body art: body piercing and tattooing among high school students in a Northeastern Italian Region. SAGE Open, v. 1, n. 3, p. 1-11, nov. 2011. Disponível em: < https://doi.org/10.1177/2158244011425833>. Acesso em: 24 mar. 2019.

COSTA, Marisa Vorraber; SILVEIRA, Rosa Hessel; SOMMER, Luis Henrique. Estudos culturais, educação e pedagogia. Rev. Bras. Educ., Rio de Janeiro, n. 23, p. 36-61, ago. 2003. Disponível em: $<$ http://www.scielo.br/scielo.php?script=sci_arttext\&pid=S1413$24782003000200004 \&$ Ing $=p t \& t$ lng $=p t>$. Acesso em: 24 maio 2019.

COUTINHO, C. P. Metodologia de investigação em Ciências Sociais e Humanas: teoria e prática. 2 ed. Coimbra, PT: Edições Almedina S. A., 2016. 
DETER-WOLF, Aaron et al. The world's oldest tattoos. Journal of Archaeological Science: Reports, v. 5, p. 19-24, jan./2016. Disponível em: $<$ https://www.researchgate.net/publication/283721737_The_World\%27s_Ol dest_Tattoos $>$. Acesso em: 10 mar. 2019.

DOMINIQUE, Roux. Revisiting (not so) commonplace ideas about the body: topia, utopia and heterotopia in the world of tattooing. In: BELK, Russel; MARTIN, Diane; SCHOUTEN, John (Editores). Consumer culture theory. Research in consumer behavior, v. 16, cap. 4, Editora: Macmillan, p. 59 - 80, dez./2014.Disponível em: <https://doi.org/10.1108/S0885211120140000016003 >. Acesso em: 10 maio 2019.

DUKES, Richard L.; STEIN, Judith A. Ink and holes: correlates and predictive associations of body modification among adolescents. Youth \& Society, v. 43, n. 4, p. 1547-1569, fev. 2011. Disponível em: <https://doi.org/10.1177/0044118X10396638 >. Acesso em: 15 fev. 2019.

DUKES, Richard L. Regret among tattooed adolescentes. The Social Science Journal, v. 53, n. 4, p. 455-458, dez. 2016. Disponível em: <http://dx.doi.org/10.1016/j.soscij.2016.08.004>. Acesso em: 10 dez. 2018.

DURBAND, Arthur C.; LITTLEON, Judith; WALSHE, Keryn. Patterns in ritual tooth avulsion at Roonka. American Journal of Physical Anthropology, v. 154, n. 4, p. 479-485, august 2014. Disponível em: <https://doi.org/10.1002/ajpa.22531>. Acesso em: 10 jun. 2019.

FARAH, M. H. S. O corpo na escola: mapeamentos necessários. Paidéia, Ribeirão Preto, v. 20, n. 47, p. 401-410, set./dez. 2010. Disponível em: $<$ http://www.scielo.br/pdf/paideia/v20n47/a12v20n47.pdf $>$. Acesso em: 5 mar. 2019.

FERREIRA, Vitor Sérgio. Becoming a heavily tattooed young body: from a bodily experience to a body project. Juventude e Sociedade, v. 46, n. 3, p. 303-337, 2014. Disponível em: < https://doi.org/10.1177/0044118X11427839>. Acesso em: 10 dez. 2018. 
FERREIRA, Vitor Sérgio. Tatuar o corpo jovem hoje: Rito de passagem ou ritual de impasse? Revista Vivência, Lisboa, v. 36, p. 137-156, 2011. Disponível em: <http://hdl.handle.net/10451/6127>. Acesso em: 20 ago. 2017.

FOSTER, Gary S.; HUMMEL, Richard L. The commodification of body modification: tattoos and piercings from counterculture to campus. 2000. Disponível em: < http://becomingwave.tumblr.com/post/81577184881/thecommodification-of-body-modification-tattoos > . Acesso em: 24 abr. 2019.

FREIRE, Ivanilda M.; DANTAS, Marayah de A. Educação e corporeidade: um novo olhar sobre o corpo. Holos, v. 4, p. 148-157, 2012. Disponível em: $<$ http://www2.ifrn.edu.br/ojs/index.php/HOLOS/article/download/729/578 >. Acesso em: 18 dez. 2018.

FRENCH, Michael T.; MORTENSEN, Karoline; TIMMING, Andrew R. Are tattoos associated with employment and wage discrimination? Analyzing the relationships between body art and labor market outcomes. Human Relations, v. 72 , n. 5, p. 962-987, 2018. Disponível em: < https://doi.org/10.1177/0018726718782597>. Acesso em: 7 mar. 2019.

GIL, Antônio Carlos. Como elaborar projetos de pesquisa. 6 ed. São Paulo: Atlas, 2017.

HENRY, J; CARSON, M. D. The medium, not the message how tattoos correlate with early mortality. American Journal of Clinical Pathology, v. 142, ed. 1 , p. 99-103, 2014 . Disponível em: $<$ https://doi.org/10.1309/AJCPDOI32FWQLUEO >. Acesso em: 20 nov. 2018.

HEYWOOD, Wendy et al. Who gets tattoos? Demographic and behavioral correlates of ever being tattooed in a representative sample of men and women. AEP, v. 22, n. 1, p. 51-56, jan. 2012. Disponível em: $<$ https://doi.org/10.1016/j.annepidem.2011.10.005Get rights and content $>$. Acesso em: 8 fev. 2019.

HONG, Bo-Kyung; LEE, Hyo Young. Self-esteem, propensity for sensation seeking, and risk behaviour among adults with tattoos and piercings. Journal 
of Public Health Research, v. 6, n. 3, p. 158-163, dez. 2017. Disponível em: $<$ https://doi.org/10.4081/iphr.2017.1107>. Acesso em: 8 nov. 2018.

KASSAR, Mônica C. M. Escola como espaço para a diversidade e o desenvolvimento humano. Educação \& Sociedade, Campinas, v. 37, n. 137, p.1223-1240, out./dez. 2016. Disponível em: $<$ http://www.scielo.br/scielo.php?script=sci_arttext\&pid=S0101-

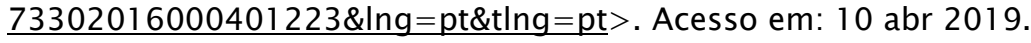

KOCH, Jerome R.; ROBERTS, Alden E.; ARMSTRONG, Myrna L.; OWEN, Donna C. Tattoos, gender, and well-being among american college students. The Social Science Journal, v. 52, n. 4, p. 536-541, dez. 2015. Disponível em: $<$ https://doi.org/10.1016/j.soscij.2015.08.001 >. Acesso em: 15 maio 2019.

LE BRETON, David. Adeus ao corpo: Antropologia e sociedade. Trad. Marina Appenzeller. Campinas, SP: Papirus, 2003.

LE BRETON, David. A sociologia do corpo. Tradução de Sônia M. S. Fuhrmann. Petrópolis, RJ: Vozes, 2006.

LIRIO, Daniel, Rodrigues. Suspensão corporal e algumas implicações intersubjetivas. 2007. 184 f. Dissertação (Mestrado em Psicologia) - Instituto de Psicologia da Universidade de São Paulo, São Paulo, 2007.

MAYERS, Lester B.; CHIFFRILLER, Sheila H. Body Art (Body Piercing and Tattooing) among Undergraduate University Students: "Then and Now". Journal of Adolescent Health, v. 42, n. 2, p. 201-203, 2008. Disponível em: $<$ https://doi.org/10.1016/j.jadohealth. 2007.09.014>. Acesso em: 10 jan. 2019.

MANZATO, Antônio José; SANTOS, Adriana Barbosa. A elaboração de questionários na pesquisa quantitativa. Disponível em: <http://www.inf.ufsc.br/ vera.carmo/Ensino_2012_1/ELABORACAO_QUESTI ONARIOS_PESQUISA_QUANTITATIVA.pdf > . Acesso em: 21 maio 2019.

MENDES, Maria Isabel Brandão de S.; NÓBREGA, Terezinha Petrucia da. Corpo, natureza e cultura: contribuições para a educação. Revista Brasileira de Educação, n. 27, p. 125-211, set./dez. 2004. Disponível em: 
$<$ http://www.scielo.br/pdf/rbedu/n27/n27a08.pdf $>$. Acesso em: 5 mar. 2019.

NEIRA, Marcos Garcia. A educação básica e os desafios nas questões relacionadas com a diversidade cultural e suas práticas curriculares. Revista de Educação Pública, Cuiabá, v. 20, n. 43, p. 323-342, maio/ago. 2011 . Doi: http://dx.doi.org/10.29286/rep.v20i43.308. Disponível em: <http://periodicoscientificos.ufmt.br/ojs/index.php/educacaopublica/article /view/308/276 >. Acesso em: 4 jul. 2019.

ORTEGA, Francisco. O corpo incerto: corporeidade, tecnologia e cultura contemporânea. Rio de Janeiro: Garamound, 2008.

PAJOR, Anna J.; BRONIARCZYK-DYŁA, G.; ŚWITALSKA, J. Satisfaction with life, self-esteem and evaluation of mental health in people with tattoos or piercings. Psychiatria Polska, v. 49, n. 3, p. 559-573, 2015. Disponível em: <http://dx.doi.org/10.12740/PP/27266 >. Acesso em: 13 mar. 2019.

PINTO, Thiago Pestana et al. Silicone líquido industrial para transformar o corpo: prevalência e fatores associados ao seu uso entre travestis e mulheres transexuais em São Paulo, Brasil. Cad. Saúde Pública [online]. 2017, vol.33, n.7, e00113316. Epub July 27, 2017. ISSN 1678-4464. Disponível em: $<$ http://dx.doi.org/10.1590/0102-311x00113316 $>$. Acesso em: 15 maio 2019 .

PIRES, Beatriz Ferreira. O corpo como suporte da arte: piercing, implante, escarificação, tatuagem. Editora Senac, São Paulo, 2005.

RAMOS, Marília Patta. Métodos quantitativos e pesquisa em ciências sociais: lógica e utilidade do uso da quantificação nas explicações dos fenômenos sociais. Mediações, Londrina, v. 18 n. 1, p. 55-65, 2013. Disponível em: <http://www.uel.br/revistas/uel/index.php/mediacoes/article/view/16807> . Acesso em: 23 jun. 2019.

ROBERTS, Derek. J. Secret Ink: Tattoo's place in contemporary American culture. The Journal of American Culture, v. 35, n. 2, p. 153-165, 2012. Disponível em: <https://onlinelibrary.wiley.com/doi/full/10.1111/j.1542734X.2012.00804.x>. Acesso em: 8 dez. 2019.

Conhecimento $\&$ Diversidade, Niterói, v. 11 , n. 24, p. $10-35$ maio/.ago. 2019 
ROBERTS, Derek J. Modified People: Indicators of a body modification subculture in a post-subculture world. Sociology, v. 49, n. 6, p. 1096-1112, 2015. Disponível em: $<$ https://journals.sagepub.com/doi/abs/10.1177/0038038514554672?jour

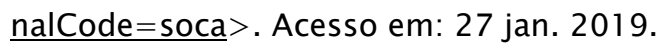

ROGGENKAMP, Hannah; NICHOLLS, Andrew; PIERRE, Joseph M. Tattoos as a window to the psyche: How talking about skin art can inform psychiatric practice. World Journal of Psychiatry, v. 7, n. 3, p. 148-158, 2017. Disponível em: <https://www.wjgnet.com/2220-3206/full/v7/i3/148.htm $>$. Acesso em: 8 fev. 2019.

SEVERINO, Antônio Joaquim. Metodologia do trabalho científico. São Paulo: Cortez, 23 ed., 2007.

SILVEIRA, Alessandra Amaral; MICHEL, Carolina Braga; SILVA, Méri Rosane Santos S. Discutindo as práicas do body modification e as possíveis produções das identidades dos jovens. Revista Textura, Canoas, v. 18, n. 37, p. 27-48, maio/ago. 2016.2 Disponível em: <http://www.periodicos.ulbra.br/index.php/txra/article/view/1821 >. Acesso em: 5 jun. 2019.

SOUSA, Diogo; IRIART, Jorge. "Viver dignamente": necessidades e demandas de saúde de homens trans em Salvador, Bahia, Brasil. Cad. Saúde Pública, v. 34, n. 10, ps. 1-11, 2018. Doi: 10.1590/0102-311X00036318. Disponível em: $\quad<$ http://www.scielo.br/pdf/csp/v34n10/1678-4464-csp-34-10e00036318.pdf $>$. Acesso em: 10 maio 2019.

STIRN, Aglaja; HINZ, Andreas. Tattoos, body piercings, and self-injury: Is there a connection? Investigations on a core group of participants practicing body modification, Psychotherapy Research, v. 18, n. 3, p. 326-333, 2008. Disponível em: <https://doi.org/10.1080/10503300701506938>. Acesso em: 15 nov. 2018.

SWAMI, Viren; GAUGHAN, Helen; TRAN, Ulrich S. et.at. Are tattooed adults really more aggressive and rebellious than those without tattoos? Body Image , v. 15, p. 149-152, set./2015. Disponível em: $<$ www.elsevier.com/locate/bodyimage $>$. Acesso em: 5 out. 2018. 
SURIS, Joan-Carles. Piercing among adolescents: Body art as risk marker. The Journal of Family Practice, v. 56, n. 2, p. 126-130, 2007. Disponível em: $<$ http://dx.doi.org/10.1080/10503300701506938>. Acesso em: 20 fev. 2019.

THOMPSON, Kathleen. Comparing the psychosocial health of tattooed and non-tattooed women. Personality and Individual Differences, v. 74, p. 122 126, 2015. Disponível em: <https://doi.org/10.1016/j.paid.2014.10.010>. Acesso em: 10 fev. 2019.

VOLPI, José H. Body modification: uma leitura caracterológica da identidade inscrita no corpo. In: CONGRESSO BRASILEIRO DE PSICOTERAPIAS CORPORAIS, XIV, IX, 2009, Curitiba. Centro Reichiano, 2009. [ISBN - 978-85-87691-163]. Disponível em: <http://www.centroreichiano.com.br/artigos/Anais2009/VOLP-Jose-Henrique-Body-modification.pdf >. Acesso em: 5 set. 2018.

WOHLRAB, Silke; STAHL, Jutta; KAPPELER, Peter M. Modifying the body: Motivations for getting tattooed and pierced. Body Image, v. 4, p. 87-95, $2007 . \quad$ Disponível em: $<$ https://www.academia.edu/8560633/Modifying_the_body_Motivations_for getting_tattooed_and_pierced >. Acesso em: 15 mar. 2019.

WOHLRAB, Silke; STAHL, Jutta; RAMMSAYER, Thomas; KAPPELER, Petter M. Differences in personality characteristics between body-modified and nonmodified individuals: associations with individual personality traits and their possible evolutionary implications. European Journal of Personality, v. 21, p. 931-951, 2007. Disponível em: $<$ https://onlinelibrary.wiley.com/doi/abs/10.1002/per.642>. Acesso em: 14 mar. 2019.

WOHLRAB, Silke; FINK, Bernhard; KAPPELER, Peter M.; BREWER, Gayle. Perception of human body modification. Personality and Individual Differences, v. 46, n. 2, p. 202-206, jan./2009. 